\title{
Virtual Reality in Cartography: Immersive 3D Visualization of the Arctic Clyde Inlet (Canada) Using Digital Elevation Models and Bathymetric Data
}

\author{
Mona Lütjens $^{1, * \mathbb{D}}$, Thomas P. Kersten ${ }^{1}\left(\mathbb{D}\right.$, Boris Dorschel ${ }^{2} \mathbb{D}$ and Felix Tschirschwitz ${ }^{1}$ (D) \\ 1 HafenCity University Hamburg, Überseeallee 16, 20457 Hamburg, Germany; \\ Thomas.Kersten@hcu-hamburg.de (T.P.K.); Felix.Tschirschwitz@hcu-hamburg.de (F.T.) \\ 2 Alfred Wegener Institute, Helmholtz Centre for Polar and Marine Research, Van-Ronzelen-Str. 2, \\ 27568 Bremerhaven, Germany; boris.dorschel@awi.de \\ * Correspondence: Mona.Luetjens@hcu-hamburg.de
}

Received: 9 January 2019; Accepted: 14 February 2019; Published: 20 February 2019

\begin{abstract}
Due to rapid technological development, virtual reality (VR) is becoming an accessible and important tool for many applications in science, industry, and economy. Being immersed in a $3 \mathrm{D}$ environment offers numerous advantages especially for the presentation of geographical data that is usually depicted in 2D maps or pseudo 3D models on the monitor screen. This study investigated advantages, limitations, and possible applications for immersive and intuitive 3D terrain visualizations in VR. Additionally, in view of ever-increasing data volumes, this study developed a workflow to present large scale terrain datasets in VR for current mid-end computers. The developed immersive VR application depicts the Arctic fjord Clyde Inlet in its $160 \mathrm{~km} \times 80 \mathrm{~km}$ dimensions at $5 \mathrm{~m}$ spatial resolution. Techniques, such as level of detail algorithms, tiling, and level streaming, were applied to run the more than one gigabyte large dataset at an acceptable frame rate. The immersive VR application offered the possibility to explore the terrain with or without water surface by various modes of locomotion. Terrain textures could also be altered and measurements conducted to receive necessary information for further terrain analysis. The potential of VR was assessed in a user survey of persons from six different professions.
\end{abstract}

Keywords: 3D terrain modelling; 3D representation; virtual reality; bathymetry; game engine; level of detail (LOD); level streaming

\section{Introduction}

Even in early human history, information from the Earth's surface was presented in maps. In the course of technological progress, contents could be depicted with more and more geographical accuracy. Today, maps are not only needed for navigation, but also as tools to better understand spatial relationships. However, geospatial problems and questions are often $3 \mathrm{D}$ in nature, yet data is traditionally illustrated on 2D surfaces, like maps or computer monitors, posing cognitive challenges for users. Therefore, many tools are offered today to compensate for the lost third dimension. These include, among others, hill shading techniques that evoke the relief of a landscape through illumination effects [1]. Another very common approach is virtual models visualized on a computer screen where the three-dimensional impression is received through rotation of the model [2].

Another solution is the presentation of 3D objects and models in virtual reality (VR). In contrast to conventional visualizations of virtual 3D models, users are immersed in a computer-generated environment and information can be obtained much more intuitively and closer to reality. Head, arm, and walking movements are transferred to corresponding motions in the virtual space, letting the user immerse and decouple from reality without leaving his current position in reality. 
The oxymoron virtual reality is defined as "a realistic and immersive simulation of a three-dimensional environment, created using interactive software and hardware, and experienced or controlled by movement of the body" [3]. The term was first introduced by author Damien Broderick in his 1982 science fiction novel The Judas Mandala. Further recent definitions are described in the literature by Dörner et al. [4], Freina \& Ott [5], and Portman et al. [6], which mostly describe VR in a broader sense, although some explicitly use non-interactive content.

This study examined the potential of VR for the representation of very large terrain data based on the Canadian fjord Clyde Inlet. The study proposed a workflow to represent large datasets in VR without reducing computer performance. Next to the degree of illusion and immersion, performance is a key factor for a pleasant VR experience. A low degree of performance not only frustrates the user but may also cause visually-induced motion sickness that can lead to symptoms of nausea, dizziness, headache, sweating, and, in worst cases, vomiting [7]. As VR systems are much more demanding than any other computer visualization tool and low performances have such a negative effect, maintaining good performance is a great challenge for developers of VR applications [8]. Many applications should also run on low or mid-end hardware to access a wide audience, thus inducing great trade-offs. The potential and user-friendliness of the application was further assessed during a user survey.

The project was carried out in 2017/2018 in cooperation between the Alfred Wegener Institute (AWI) of Helmholtz Centre for Polar and Marine Research in Bremerhaven and HafenCity University (HCU) Hamburg, Germany.

\section{Related Work}

Due to recent advances in hardware and software technology, virtual reality is becoming ubiquitous and accessible for the general public, as several companies have brought low-cost high-quality head-mounted systems to the market. However, technological progress and its accessibility are mainly owed to the wealthy video game industry that can effort to invest so much in pioneering industry [9]. Therefore, many applications are designed for video games and, only recently, more and more other disciplines deploy VR. So far, VR is today successfully used for virtual surgery, virtual therapy, flight and vehicle simulations and cultural heritage [10]. At HCU Hamburg, several VR projects have already been realized. The old town house of the city Bad Segeberg was presented as one of the first virtual museums for an immersive visit with the HTC Vive as head mounted display (HMD) [11]. Two historical cities (including the surrounding landscape) were developed as VR applications for a virtual tour in past ages: Duisburg in 1566 [12] and Segeberg in 1600 [13]. Two religious cultural monuments are available as VR applications: the Selimiye Mosque in Edirne, Turkey [14], and the wooden model of Solomon's Temple [15].

As can be seen, a variety of works about VR implementations can be found in current research works. However, with respect to terrain visualizations in VR, only a few related research papers are known. An overview on game engines and their possibilities to import and design terrains is given by Mat et al. [16]. Further options and limitations of game engines for landscape visualizations are outlined in Reference [17], including a representation of a small-scale landscape in Unreal Engine. Thöny et al. [18] propose ideas for improving scientific terrain rendering with level of detail (LOD) algorithms and different rendering techniques, though none have been tested with real-world datasets. Applications of small-scale real-world terrain data using the game engine Unity have been proposed by Mat \& Mahayudin [19] and Wang et al. [20]. While Mat \& Mahayudin [19] visualize an oil palm tree plantation to support the database management system helping decision-making processes, Wang et al. [20] simply represent two research stations in Antarctica in their natural environment. A study about working with large-scale terrain visualizations is outlined in Reference [21]. They propose a tile-based rendering system in combination with LOD and texture LOD algorithms to produce seamless presentations of large worlds with high rendering performance. However, this research concentrated on 3D GIS applications and was not implemented in VR. At this stage, no research work regarding large-scale terrain presentations in VR is known to the authors. 


\section{Methodology}

\subsection{Project Workflow}

The entire region of the fjord Clyde Inlet on Baffin Island, Canada, was visualized in virtual reality above and below the water surface. Special focus was given to achieve a realistic 1:1 representation of the fjord, including several measuring tools and the option to change the coloration depending on the field of application (see Chapter 5). The project has been roughly divided into three major phases of development (Figure 1): (1) Defining the area of investigation and acquiring necessary datasets, (2) combining all datasets to generate a coherent digital elevation model, (3) VR implementation using the game engine Unreal Engine 4 (UE4).
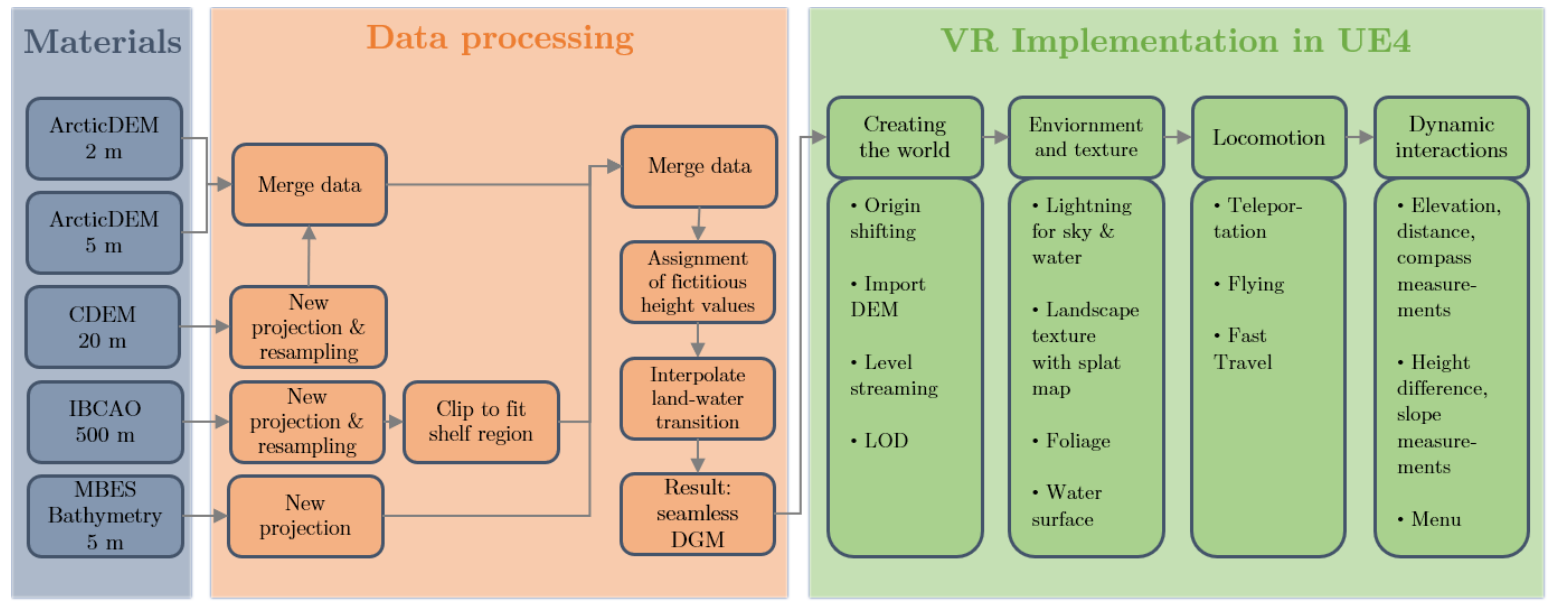

Figure 1. Workflow for the development of the virtual reality (VR) application.

\subsection{Area of Investigation and Materials}

The area of investigation comprises the Arctic fjord Clyde Inlet on northeastern Baffin Island, Canada. With its mouth opening into the Baffin Bay, the dimensions of the investigated area comprise $160 \mathrm{~km} \times 80 \mathrm{~km}$. With $-850 \mathrm{~m}$ below mean sea level (MSL), the lowest elevation of the area is situated at the shelf edge. The highest peak of $1895 \mathrm{~m}$ above MSL is located at the mountain peaks of Baffin Island's interior plateau. The Baffin Mountains are part of the Arctic Cordillera mountain range-a northeastern flank of the Canadian Arctic Archipelago. The $120 \mathrm{~km}$ long fjord system Clyde Inlet stretches from Baffin Bay south-westwards towards Barnes Ice Cap. It includes three major geographic features that branch roughly $20 \mathrm{~km}$ from the mouth of the fjord: Patricia Bay in the North, Clyde Inlet in the West, and Inugsuin Fjord in the South (Figure 2).

To visualize the area, several bathymetric and terrestrial elevation datasets were used. The following table (Table 1) summarizes the utilized datasets.

Table 1. Utilized elevation data.

\begin{tabular}{ccc}
\hline Type & Origin & Resolution \\
\hline Bathymetric & Collected from the cruise MSM66 in 2017 in collaboration with & $5 \mathrm{~m}$ \\
Bathymetric & Alfred-Wegener Institute (AWI) & $500 \mathrm{~m}$ \\
Terrestrial & International Bathymetric Chart of the Arctic Ocean (IBCAO) [22] & $2 \mathrm{~m} \mathrm{\&} \mathrm{m}$ \\
Terrestrial & ArcticDEM [23] & $\sim 20 \mathrm{~m}$ \\
\hline
\end{tabular}




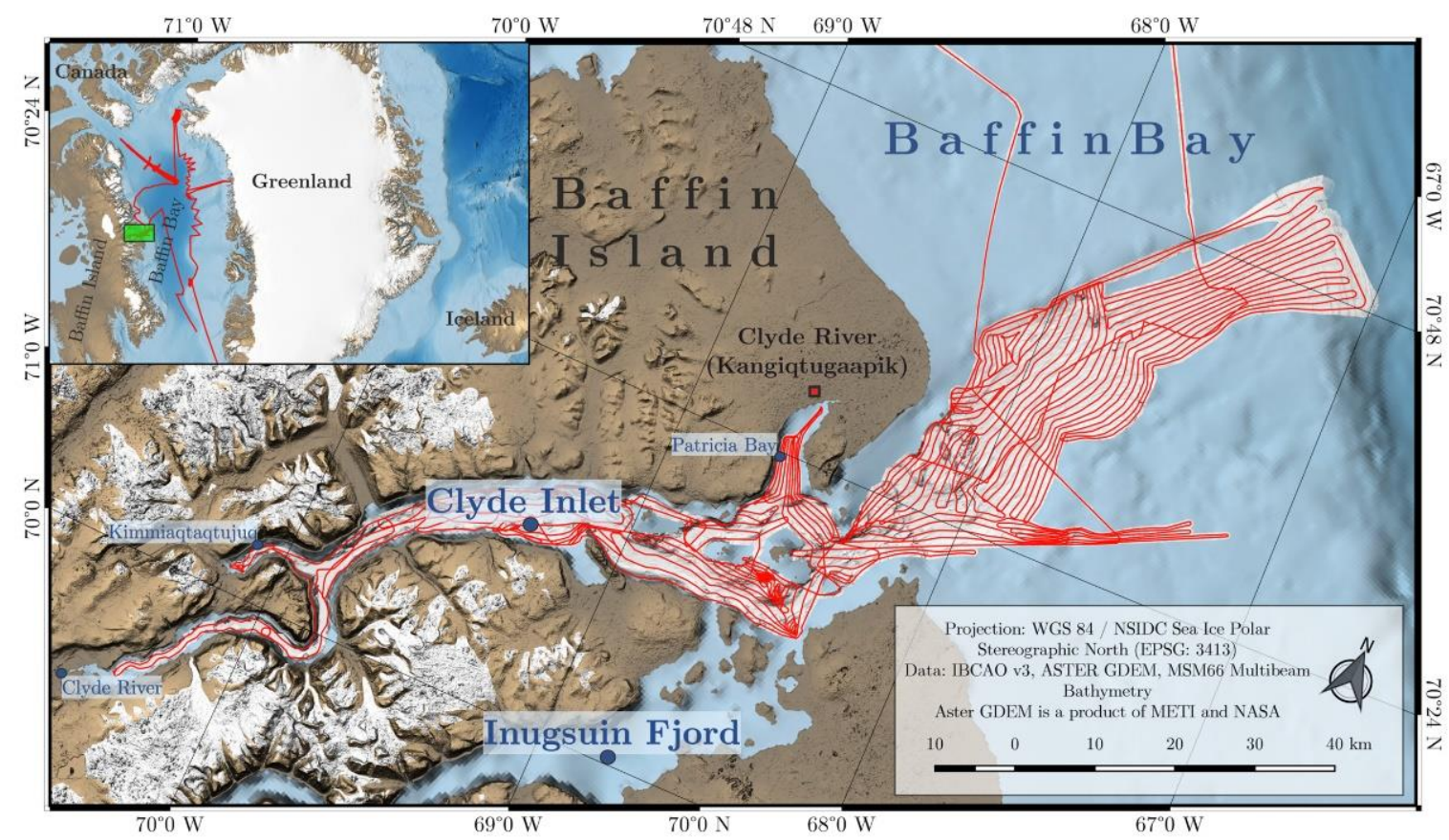

Figure 2. Overview of Clyde Inlet showing track lines (red) of cruise MSM66.

\subsection{Data Processing and Generation of Coherent Digital Elevation Model}

Bathymetric data was collected during the expedition MSM66 in 2017 conducted by AWI in Bremerhaven, Germany, and the Center for Marine Environmental Sciences (MARUM) in Bremen, Germany. The acquisition took place onboard the German RV Maria S. Merian, using a permanently installed $12 \mathrm{kHz}$ multibeam echosounder. With 163 survey hours and a track length of $2760 \mathrm{~km}$, Clyde Inlet's bathymetry was captured extensively. To prevent refraction errors, eleven well-distributed sound velocity profiles were taken during the survey. The acquired data was cleaned of major outliers and corrected for navigation and attitude errors. In the end, from all accepted soundings, an underwater digital elevation model (DEM) was computed with the best possible resolution of $5 \mathrm{~m}$ [25].

In contrast to the bathymetric data, the terrain above water can be measured very efficiently and with high resolution from aerial or satellite image data. The ArcticDEM with a $5 \mathrm{~m}$ resolution served as the base elevation model. Present gaps were closed with the $2 \mathrm{~m}$ resolution model, and all residual holes were filled with the Canadian Digital Elevation Model (CDEM) (Table 1). The CDEM, however, had to be resampled and reprojected to fit the projection and resolution of the main model. The NSIDC (National Snow and Ice Data Center) Sea Ice Polar Stereographic North projection was chosen, since it presents the fjord in the most compact way, which is essential for the work in the VR game engine. In addition, the CDEM dataset had to be slightly smoothed to reduce the existing pixelated surface, as spatial aliasing is greatly visible and very unaesthetic in VR. Throughout all processing steps, the merged terrestrial digital elevation model yielded only minor elevation changes of several meters from the original source datasets.

Finally, in order to merge the bathymetric and terrestrial elevation models, the transition between land and water had to be examined. Since bathymetric data sampled on the vessel can never reach the shoreline due to limited field-of-view of the echo sounder and satellite or aerial photography never images underwater topography, a transition zone will always be uncharted. Therefore, this transition zone within the fjord was interpolated from adjacent terrain data as the area is relatively narrow ranging from $30 \mathrm{~m}$ to $1000 \mathrm{~m}$. However, several precarious places were identified in the elevation models where the linear interpolation would distort shorelines of mainland and islands. To account for any distortions, a negative cell value of $-5 \mathrm{~m}$ was applied to these areas (Figure 3 ). This value 
was chosen to ensure a relatively smooth transition but also to maintain the shoreline as precisely as possible.

The region from the coastline to the shelf edge was only covered to one fourth with multibeam bathymetric data. The remaining bathymetry was covered with International Bathymetric Chart of the Arctic Ocean (IBCAO) data seaward of approximately $1000 \mathrm{~m}$ offshore due to its low resolution of $500 \mathrm{~m}$. In the end, all datasets could be merged into a single overall digital elevation model converted to the file format *.r16 and ready to be imported into the VR game engine Unreal Engine 4.

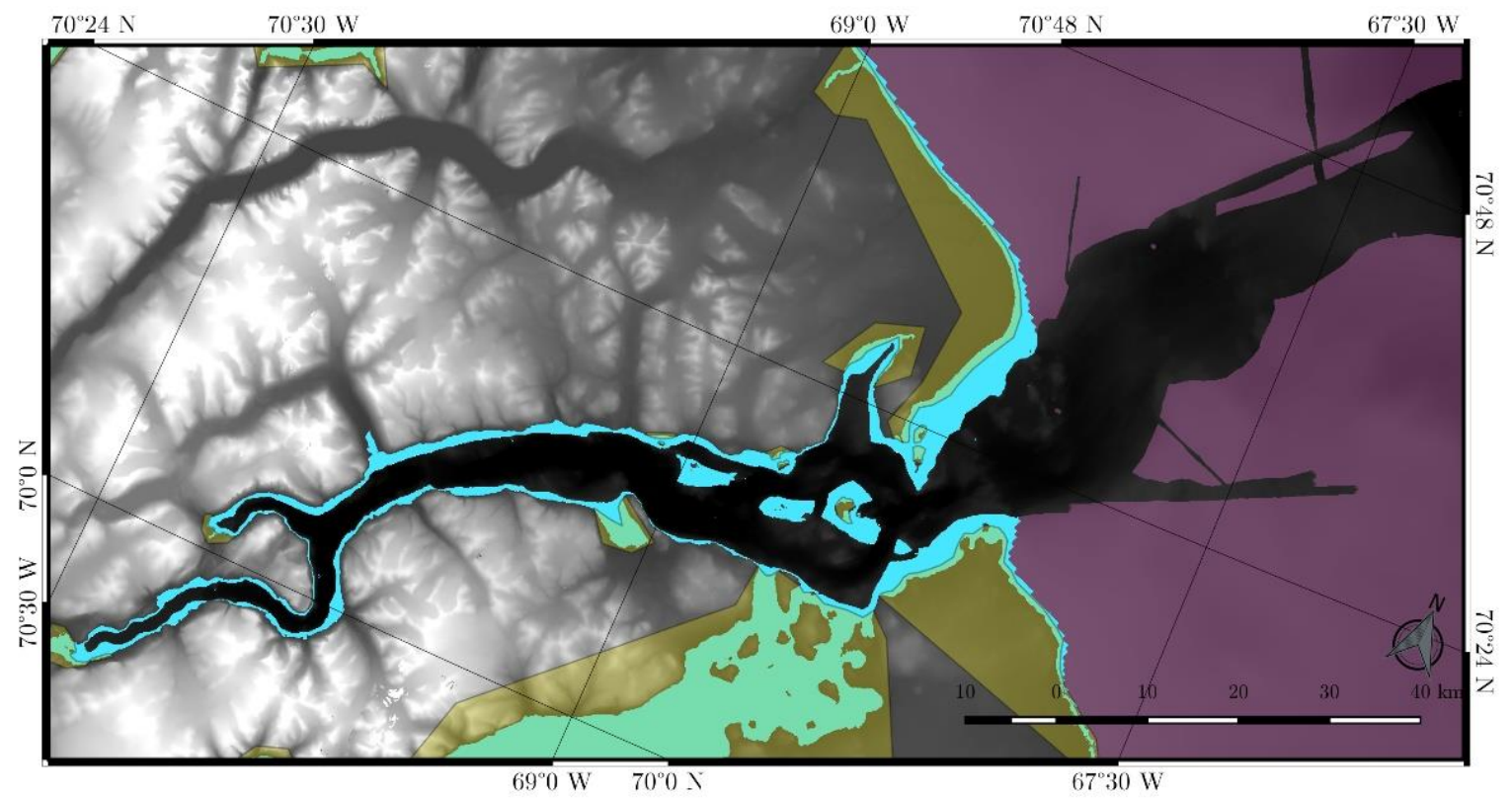

Figure 3. Final digital elevation model (DEM) showing the IBCAO data (pink), interpolated transition (blue) and masks for precarious locations (olive green).

\subsection{Game Engine Unreal and VR System HTC Vive}

A game engine is a software-development environment designed to create video games for consoles, mobile devices, and personal computers. Its main functionality is typically comprised of a rendering engine for 2D or 3D graphics to visualize textured 3D models, a physics engine or a collision detection to interact with objects, an audio system to emit sound, scripting, animation, artificial intelligence, streaming, and performance management. A game engine is a powerful platform to display 3D terrain data in VR, because it provides the functionalities necessary for the user to be immersed in the virtual world.

At present, several game engines offer free access for developers, such as the engine Unity from Unity Technologies, the CryEngine from the German development studio Crytek, and the engine Unreal from Epic Games. A current overview and comparison of different game engines can be found in Reference [26,27]. Selection of the appropriate engine for a project is based on the components mentioned above and its adaptability to the existing work process. For this project, the game engine Unreal was chosen because it implements-opposed to other engines-the visual scripting language so-called Blueprints. Visual programming with Blueprints does not require the writing of machine-compliant source code and enables a much easier entry into the development environment for users with little programming knowledge. In addition, Unreal offers sufficient access to documentations, tutorials, and asset stores. Due to limited time for this project, no other engine was tested with the proposed workflow.

HTC Vive (www.vive.com) is a virtual reality headset (Figure 4) for room-scale VR. It was developed by HTC and Valve Corporation, released on 5 April 2016, and is currently available on the market for EUR 599, while the new HTC Vive Pro (complete edition) costs EUR 1399 (January 2019). 
Basic components are the headset for the immersive experience, two controllers for user interactions, and two "Lighthouse" base stations for tracking the user's movement (Figure 4). The device uses a gyroscope, accelerometer, and laser position sensor to track the head's movements as precisely as one-tenth of a degree [28]. Wireless controllers in each hand, with precise SteamVR-tracking, enable the user to freely explore and interact with virtual objects, people, and environments. The VIVE-controller is specifically designed for VR with intuitive control and realistic haptic feedback. The Lighthouse system uses simple photo sensors on any object that needs to be captured. By sweeping a line laser over an object, the time difference of arrival is calculated over various photo sensors to estimate a 6-DoF pose. To avoid occlusion problems by non-penetrative laser light and to increase tracking accuracy, this is carried out with two diagonally positioned Lighthouse stations that light the space. Figure 4 (right) shows the setup of the VR system HTC Vive, including the interaction area (blue).

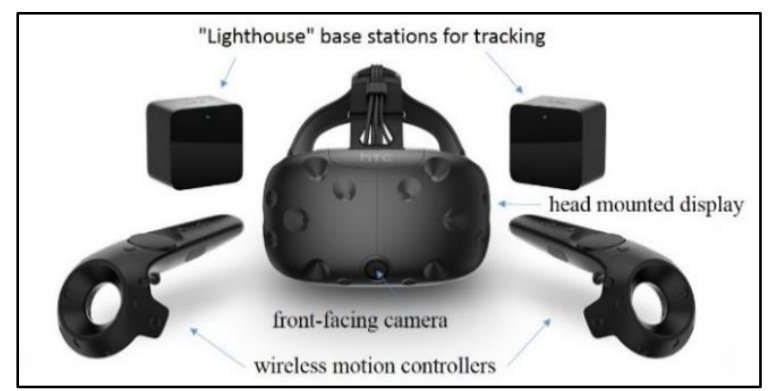

(a)

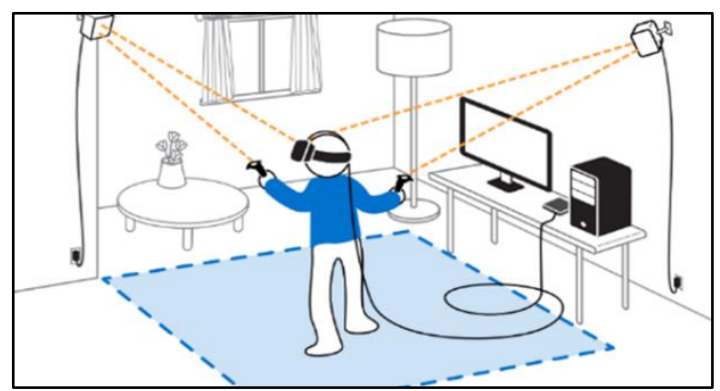

(b)

Figure 4. Components (a) and schematic setup (b) of the VR system HTC Vive with interaction area (blue) [29].

\subsection{Implementation into Virtual Reality}

The virtual reality application was developed using the game engine Unreal Engine 4 (UE4) version 4.17.2. An indispensable tool for the realization of large-scale terrains is UE4's World Composition, which when enabled allows the import of tiled landscapes that are greater than the hard-coded maximum world size of $20 \mathrm{~km}$ [30]. The feature World Origin Rebasing must also be enabled, which resets the origin of the coordinate system of all Actors after an arbitrary amount of about $5 \mathrm{~km}$ to the current position of the user. Without enabling this feature, objects that are placed more than $5 \mathrm{~km}$ away from the world origin, start to experience negative effects, such as unstable physics simulation.

The final DEM was imported as a tiled landscape with $16 \times 8$ tiles each containing $2017 \times 2017$ pixel. To ensure a real life 1:1 presentation, a specific scaling factor was applied for the $X Y$ and $Z$ extent. The scaling for $X Y$ was calculated by dividing the overall width of the terrain by the number of pixels in $X$. Since the ratio of the terrain size is $2: 1$, the scaling is identical for $X$ and Y. To adjust the vertical scale, the total vertical range $(2741 \mathrm{~m})$ was multiplied by the constant 0.1953125 [31]. Subsequently, all 128 tiles of the digital elevation model were imported. Each tile has a size of $10 \mathrm{~km} \times 10 \mathrm{~km}$, which corresponds to eight million triangles.

Since the real-time visualization of 128 tiles ( $1 \mathrm{~GB}$ ) with a resolution of $5 \mathrm{~m}$ would lead to massive computational issues, a combination of level streaming and LOD was applied. Level streaming is a tool in UE4 that only renders tiles with a specific streaming distance from the user. All tiles that exceed that distance do not consume memory space and are kept invisible from the user. For this project a streaming distance of $10 \mathrm{~km}$ was chosen to only visualize adjacent tiles. All streamed tiles received an automatic LOD system by UE4, which radially reduces the triangles relative to the distance from the user. The LOD system contains six levels of details, starting with the highest LOD represented by the color white and ending with the lowest LOD represented by pink (Figure 5). Tiles that are not streamed with the highest resolution could still be made visible by applying a developer specified LOD. For each tile, a developer-specified triangle reduction of $99.97 \%$ was computed, in addition to the 
automatic UE4 LOD system. Now each tile further exists with a total amount of 2048 triangles. Those tiles receive another streaming distance set to the maximum of $100 \mathrm{~km}$, which is applied after the first $10 \mathrm{~km}$ streaming distance. Consequently, all low-resolution tiles will be loaded after the distance of the high-resolution tiles, making all parts of the entire landscape always visible. Since the triangle reduction is so low, additionally, normal textures were applied to each distant tile emphasizing the topography of the terrain. Normal textures provided further information about the relief of each specific tile, and the positive visual effect is illustrated in Figure 6.

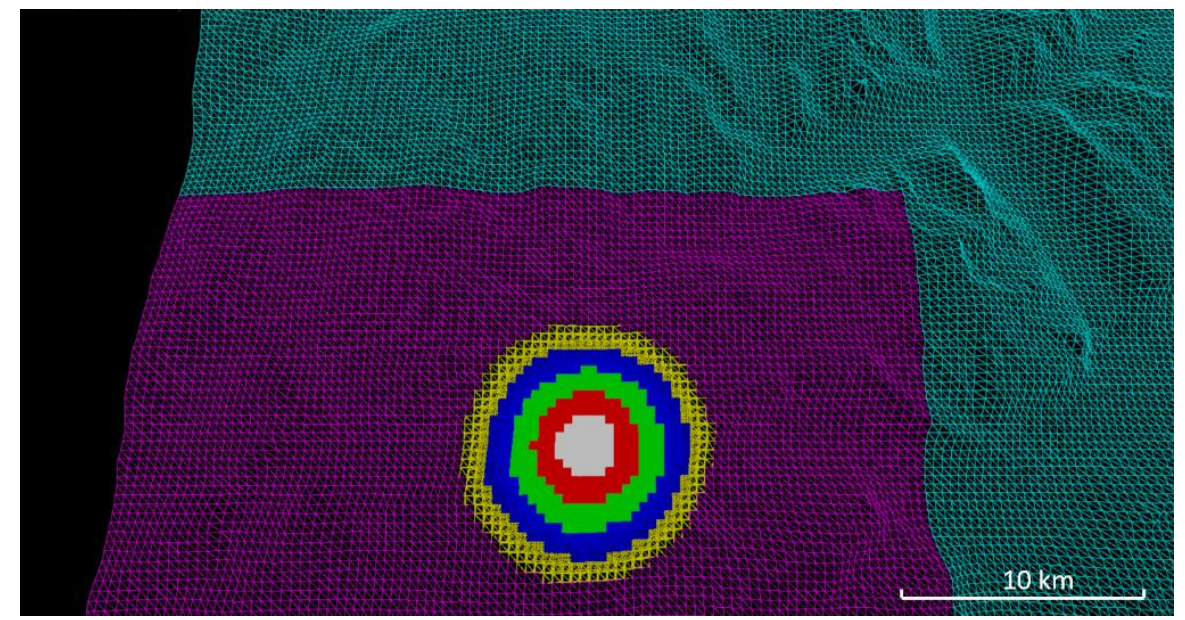

Figure 5. Overall level of detail (LOD) system, including automatic LOD generation by UE4 for all loaded tiles (white, red, green, yellow, and pink) and manual LOD generation for all tiles that are not streamed (cyan).
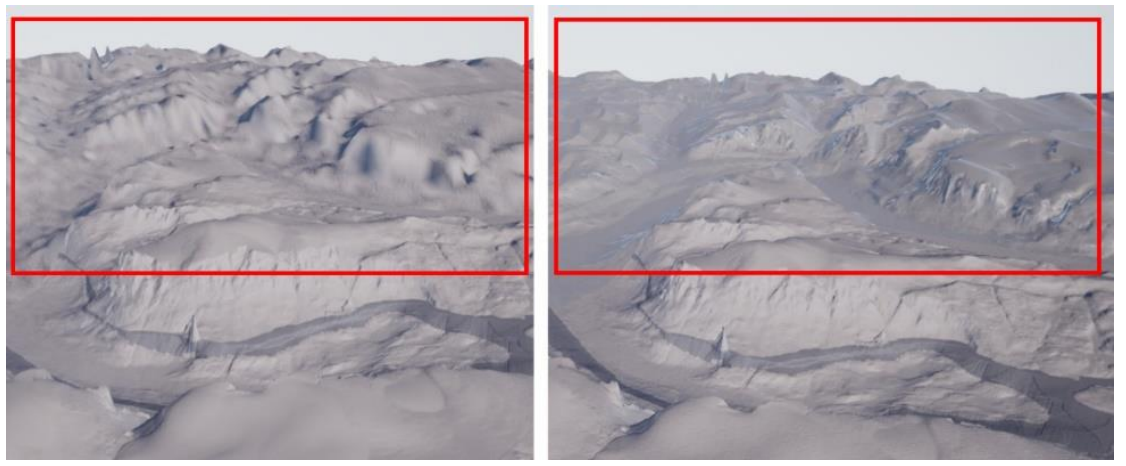

Figure 6. Distant terrain without normal texture (left) and with normal texture (right).

To receive a realistic appearance of the virtual environment, natural effects, such as moving water, sunbeams, shadows, moving flowers, grass, wind, and flying seagulls, were programmed into the VR application. The texture of the landscape was designed to receive both a realistic and functional view of the terrain. Each geographical feature and dataset received a different texture. In addition, the user could switch between textures, according to the related personal practical background and questioning. To guarantee a correct placement of textures, a splat map was developed (Figure 7).

A splat map is a greyscale or RGB image that color-codes information to ensure correct placement or blending of textures. Each specific area received a different greyscale value assigning the corresponding texture to its area. In total, five different territories make up the landscape. The terrestrial elevation model can be displayed in grey highlighting geological features or in natural colors. The natural coloration was realized in combination with the Randolph Glacier Inventory (RGI) dataset [32], representing areas of permanent glaciation. The bathymetric multibeam dataset could be displayed in grey, according to its sediment classification or in rainbow colors related to the water depth. To 
differentiate this dataset from the interpolated and IBCAO data, the latter were shaded dark grey. Furthermore, a simple version of the texturing algorithm was assigned to each single 2048-pixel low-resolution tile, because these tiles do not share an overall landscape Actor that organizes their information and location. Therefore, the splat map could not be stretched over the entire extent of the terrain but must be split into $16 \times 8$ mosaics to provide each low-resolution tile with its corresponding mosaic tile.

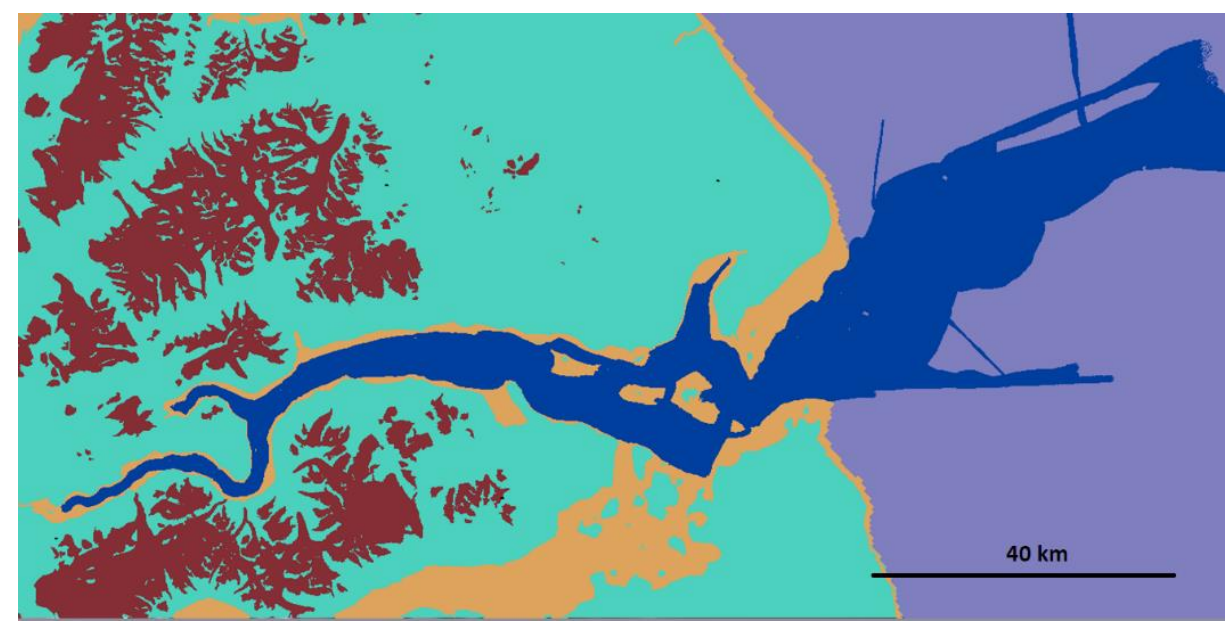

Figure 7. Splat map defining five territories: MSM66 bathymetry data (blue), IBCAO data (purple), transition (orange), the terrestrial elevation model (turquois), and glaciers (ruby).

The navigation in the VR application was realized by three different modes of locomotion. The user could either fly with manually varying speed, jump up to $20 \mathrm{~m}$ on the ground, or teleport to fixed waypoints. The application also included measurement tools, such as the reading of elevation above MSL, distance to a point, and compass bearing. Furthermore, height differences between two points could be determined with the help of the controllers. To organize all functionalities, an in-game accessible menu (Figure 8) was programmed, as well.

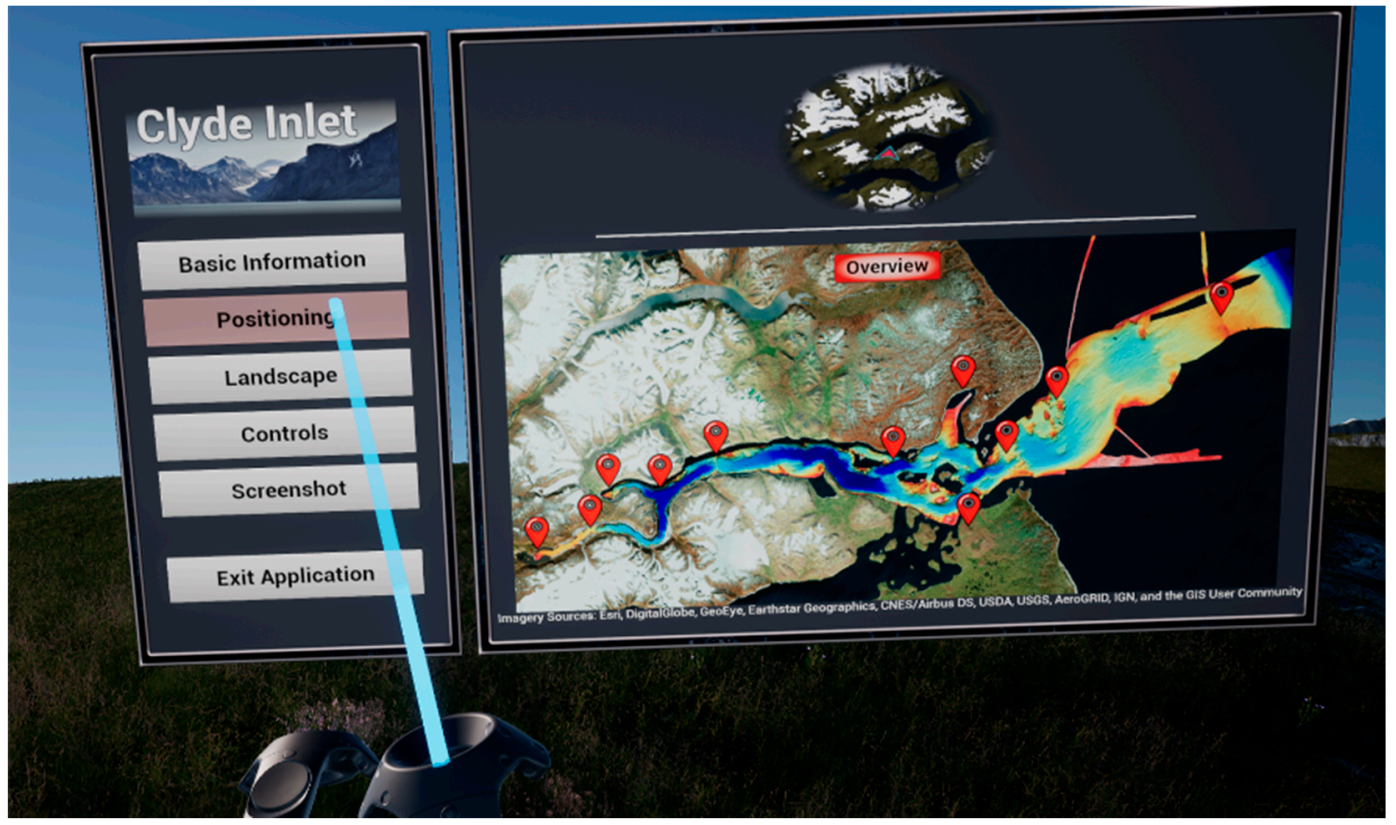

Figure 8. The in-game accessible menu with six different menu pages. 


\section{Results}

The results comprised the VR visualization of the terrain stretching from the head of Clyde Inlet until the continental margin of Baffin Bay. All in all, five different datasets were used to create the terrain above and below the water surface, with the best possible resolution of $5 \mathrm{~m}$. Furthermore, several textures, locomotion modes, and measurement tools were adopted to interact and work with the terrain (Figures 9-13). Figure 11 shows the quality of the virtually generated landscape (bottom) compared to the real fjord environment illustrated in a photograph (top).

Overall, no major loss of accuracy could be detected, as the processing of the digital elevation models yielded only minor inaccuracies of several meters. The import and scaling of the terrain in UE4 was also accurate as test measurements showed deviations of only 1 to $3 \mathrm{~m}$.

The performance of the real-time visualization was tested on a laptop (Intel ${ }^{\circledR}$ Core $^{\mathrm{TM}} \mathrm{i7}-6700 \mathrm{HQ}$ @2.60 GHz, a NVIDIA GeForce ${ }^{\mathrm{TM}}$ GTX 1060, and 16 GB RAM) and a personal computer (Intel ${ }^{\circledR}$ Core $^{\mathrm{TM}}$ i7-6700K @4.00 GHz, a NVIDIA GeForce ${ }^{\mathrm{TM}}$ GTX 1080, and 16 GB RAM). The application was running on both computers, although the laptop had a very high central processing unit (CPU) usage and the loading of tiles was not as smooth compared to the personal computer. We therefore assumed that the application would not run on mobile devices, such as tablets or smartphones, and was thus not suitable for low-end devices.

The performance on the personal computer yielded a frame rate of 44 frames per second (FPS), while navigating slowly through the virtual world. Ideally, a VR application should run at a frame rate that complies with the refresh rate of the head-mounted display, which is $90 \mathrm{~Hz}$ with the HTC Vive specification [33]. Standard recommendations from literature suggest a frame rate of at least 60 FPS [9]. Even though the recommendations were not met, stuttering or dropping frames could not be detected while navigating slowly through the terrain. However, when the speed was increased, stuttering was noticeable each time a new level was loaded, or the world origin was shifted. No motion sickness nor any other form of discomfort was identified by various test persons. To improve the frame rate, the computational power could be simply increased by using improved CPU's and GPU's or by checking and enhancing performance and profiling statistics of a rendered scene in UE4. More information on two rendering techniques regarding this application is given in Reference [25].

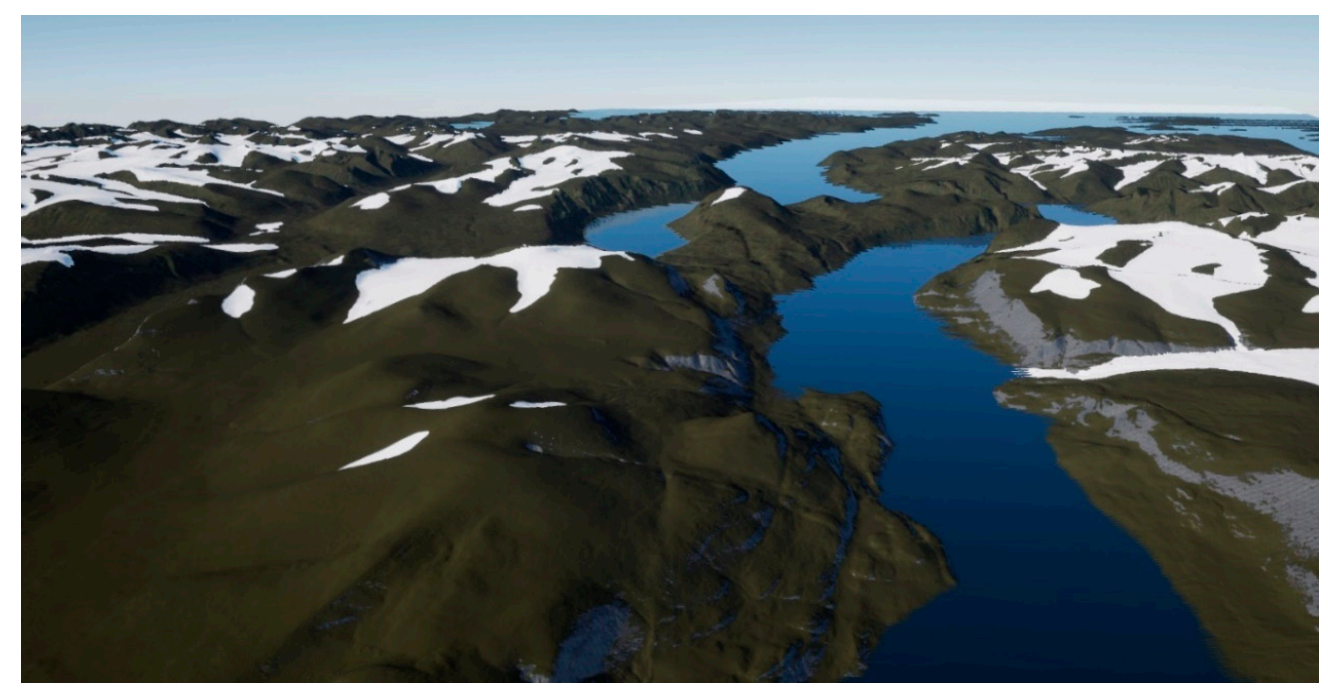

Figure 9. Landscape scenery in UE4 with natural terrestrial coloration. Even distant landscape parts are visible. 


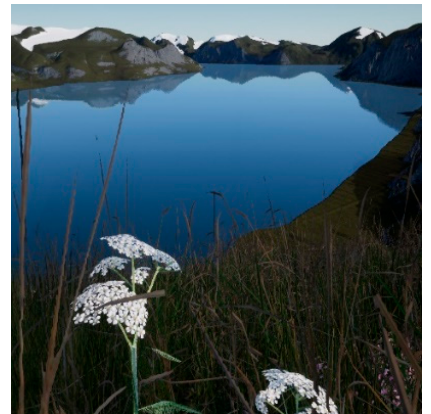

(a)

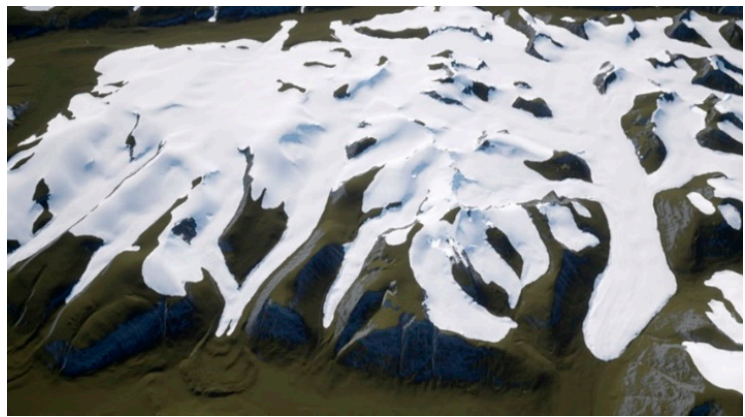

(b)

Figure 10. Landscape scenery in UE4 with natural terrestrial coloration, foliage, and water surface (a) and glaciers using the Randolph Glacier Inventory (RGI) dataset (b).
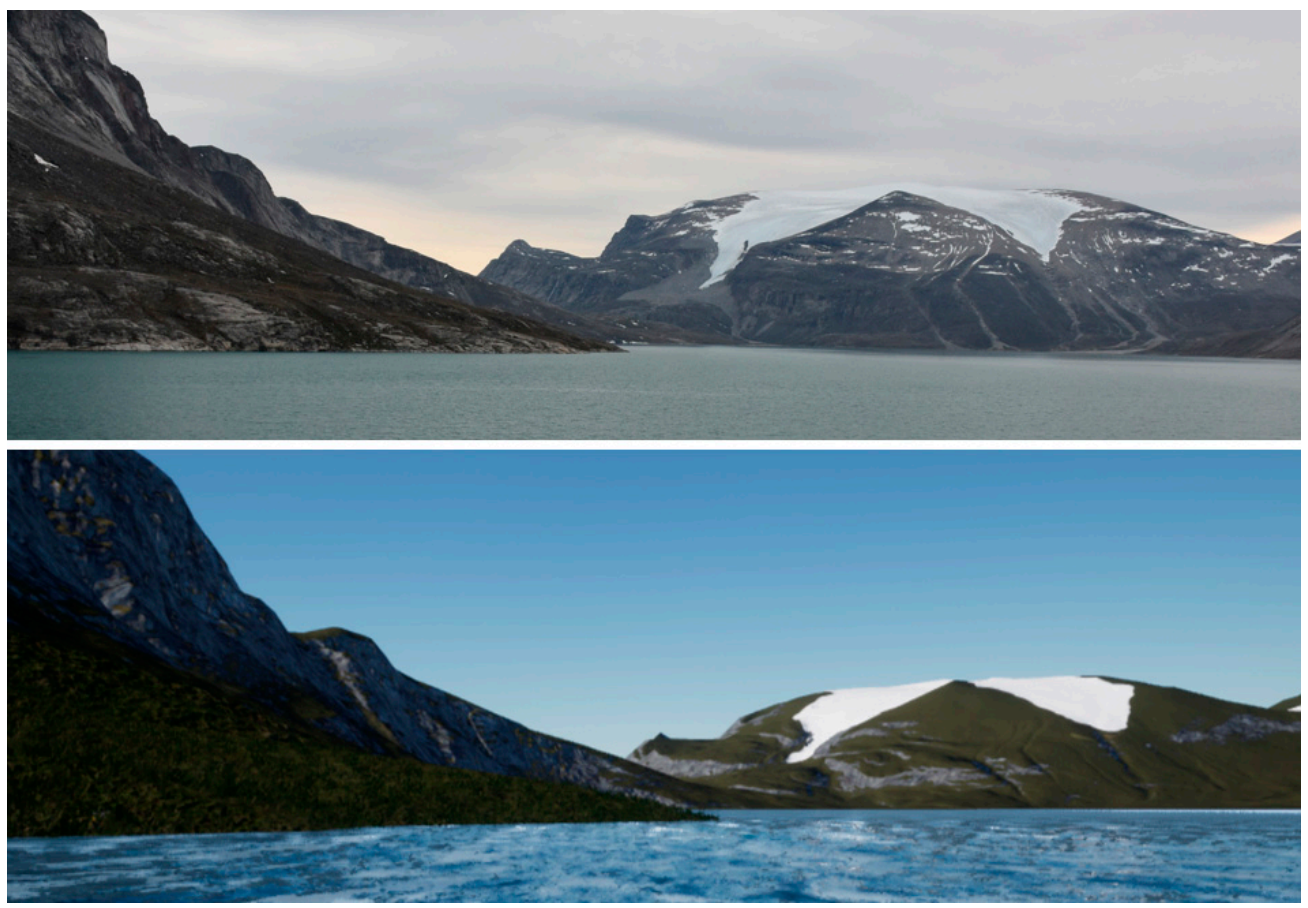

Figure 11. Comparison of the real fjord environment in the photo (top) with the virtual generated environment (bottom).

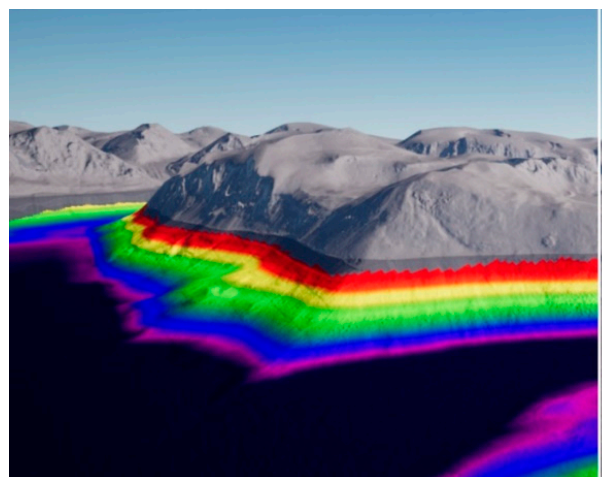

(a)

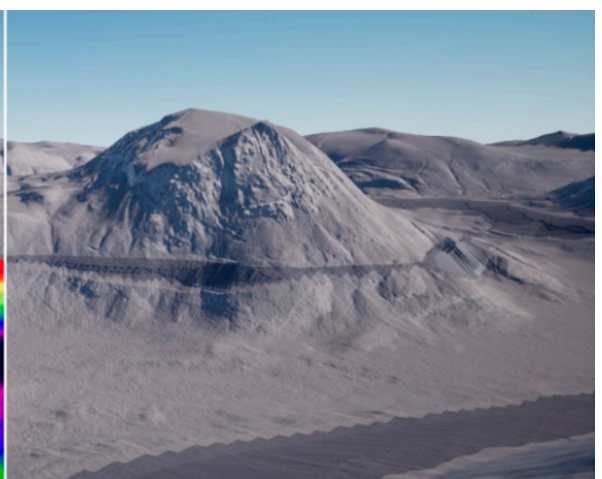

(b)

Figure 12. Landscape scenery in UE4 without the water surface depicting the grey coloration for the terrestrial terrain. The bathymetry is colored in rainbow colors relative to the depth (a) or light grey for the MBES bathymetry and dark grey for the transition zone (b). 


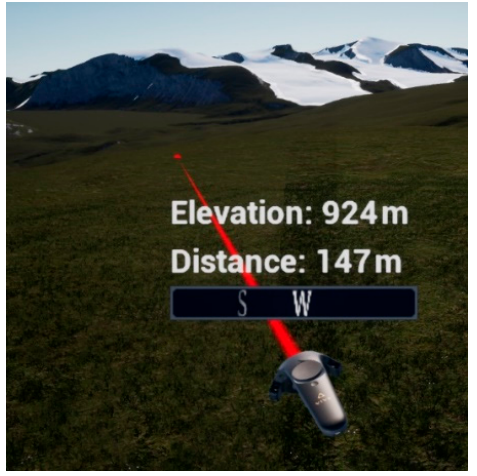

(a)

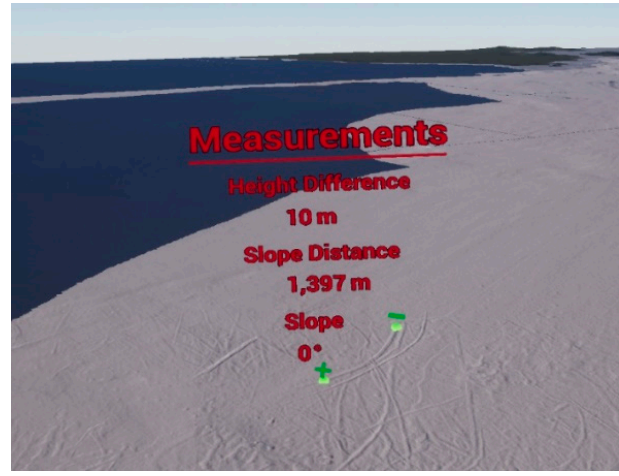

(b)

Figure 13. The left and right motion controller in VR where the left controller holds the elevation, distance, and compass measurements and the right controller holds the locomotion possibilities (a). The height difference, slope distance, and slope measurements can be conducted between two points (b).

\section{Usability and Utility Assessment}

To discover the benefits, as well as limitations, of VR visualizations, a user survey was conducted with ten participants representing the following professional fields: hydrography, geology, geography, archaeology, civil engineering, and, lastly, the tourist industry. The interviewees (age 30-50) had a variety of functions, such as professor, Ph.D. candidates, a graduate engineer, and a general manager, and worked for different universities, institutions, and authorities. Each participant used the VR application for about $30 \mathrm{~min}$, followed by a qualitative questionnaire with four questions regarding the usability and six questions considering the utility of VR. The questionnaire and its evaluation are comprehensively documented in Reference [25].

All participants perceived the application as very user-friendly and easy to use. The survey also provided a good overview of all functionalities, since they could be looked up in the menu. A good orientation was provided by a compass and a mini-map. Most importantly, no participant felt uncomfortable while navigating through the virtual world nor felt any form of motion sickness. The advantages of VR visualizations are versatile and different to each specific field. Yet, all disciplines received a better impression of the terrain compared to $2 \mathrm{D}$ visualizations. All measuring tools were also helpful to get necessary information from the terrain and to estimate the spatial dimensions.

For hydrographers, the quality of bathymetric data and its representation plays a crucial role. Since outliers in the data are very easily detectable in a three-dimensional environment, VR could act as a supportive tool for quality assessment routines. Lots of time can also be saved when outliers or hazardous material are easily identified. VR, furthermore, proved to be helpful for terrain analyses, especially considering backscatter investigations. Emitted sound signals that are backscattered from the seabed towards the hydrophone are not only investigated by their travel time but also by their intensity. Different intensities could provide information on the sediment characteristics as the intensity of the signal varies with the hardness, softness, and roughness of the seabed [34]. However, the intensity also varies with the inclination of the terrain and the incidence angle of the signal being the strongest in nadir section and weakest in the outer sections. While the latter cannot be solved with VR, the inclination, however, can be investigated. As backscatter information is draped above the 3D terrain, correlations between sound intensity values and the slope of the terrain can be made. For geologists and geographers, VR could also serve as a helpful tool to intuitively capture measurements and information, such as the inclination of the terrain and the dimension of morphological landforms. 
A VR application can also be used to support the exchange between scientists, such as biologists, geographers, geologists, etc., who work on the same project with the same dataset but at different physical locations. Within VR, everybody can work simultaneously and communicate while being physically miles apart. This feature, however, was not implemented for this project, but it was already implemented in other projects of HCU Hamburg, which are presented in Reference [12-15].

For civil engineers, VR is also beneficial for the representation of terrain data. Since the presentation is very intuitive and self-explanatory, VR systems can be used to convince decision-makers or be displayed at civic participations showcasing new projects and reducing misconceptions. For the planning of constructions, VR could be implemented to show or hide various construction designs for decision-making processes and could be used for site selections.

Archaeologists receive a better impression for dimensions of sites, which is not possible when investigating simulations. Moreover, VR is regarded as a cost-effective tool to reconstruct places or buildings in 3D when the original site can no longer be visited. Virtual immersive reconstructions are, however, not only preferred over physical reconstructions due to financial reasons, but they also offer the possibility to investigate visual axes in a very easy way. Ancient visual axes are used to check assumptions, such as "Why would Romans construct their weir system in an Egyptian valley which is surrounded by mountains from which it is easily attackable?" Exploring the terrain in a virtual application will help understanding ancient decisions and current hypotheses. Moreover, weather conditions can be easily adjusted to observe sites with rain, sunlight, fog, snow, night, and so forth.

For tourism, VR is useful to demonstrate journeys so that potential travellers can receive a more in-depth perception of the trip. It will also be effective to showcase trips at fairs in order to attract potential customers.

Having listed numerous advantages and potential applications for different disciplines, VR applications programmed using the game engine Unreal Engine 4 still have severe disadvantages. A major disadvantage is the very limited possibility to import or export spatial datasets. Vector file formats, such as shapefile, are not supported, and raster datasets can only be imported in graphics file formats without spatial reference since no coordinate transformation algorithm is implemented.

The only way to provide a spatial link is to import raster datasets with the same extent, scale, and position as the terrain in UE4. However, currently, the greatest resolution of imported graphic formats is 8192 pixels, resulting in a very pixelated display when scaling the image over a large terrain. Individual objects can be placed onto the terrain with spatial reference, though only by taking the $\mathrm{XY}$ distance from the top-left corner of the terrain to the specific point (within any GIS software) and transferring the distance onto the terrain in UE4. The default coordinate origin in UE4 is the top-left corner, and the terrain must have the same extent in both the GIS software and in UE4. Using this method, coordinates within VR can be accessed, but this is by far very time-consuming and inefficient for most applications. Applying a coordinate transformation algorithm is generally possible, nevertheless it will arouse quite a challenge since the origin of the coordinate system in UE4 changes after an arbitrary distance for large terrains. To overcome this, one would have to use either small terrain sizes of less than $5 \mathrm{~km} \times 5 \mathrm{~km}$ and disable World Origin Rebasing or initiate World Origin Rebasing manually, which is in fact very time-consuming, especially for larger terrains with lots of tiles.

Another disadvantage is the time-consuming workflow of the project, since all teleportation waypoints and normal maps must be set manually. The hardware setup can also be very tedious, as the HTC Vive Lighthouse tracking system-used for this project-with base stations has to be deployed in a room and an interaction area has to be calibrated (Figure 4).

\section{Conclusions and Outlook}

In this contribution, it could be shown that large, high-resolution terrain datasets can be visualized in a virtual reality application by incorporating tiling, level streaming, and LOD algorithms. The fusion of the different terrain datasets above and below the water surface was achieved by linear interpolation. The application could run on mid-end computers with 44 FPS, providing a sufficient 
performance. No participant felt uncomfortable or motion sick. The VR application was perceived as overall user-friendly and all survey participants received a better idea of the terrain topography compared to a two-dimensional representation. However, the game engine did not offer optimal data import and export possibilities and the spatial relation via coordinate systems was not given. Nevertheless, the potential of VR for different fields of occupation could be demonstrated within the framework of this developed VR application. A lot of advantages were assessed which could improve the work of hydrographers in terms of backscatter analysis and data quality considerations, archaeologists regarding ancient visual axes, civil engineers concerning decision making processes, geologists with regard to geological interpretations and geomorphological analyses, or tourism for presenting their journeys at fairs. It can be assumed that the advancement of game engines for visualization of geographical data and large terrain datasets will certainly continue to support the increasing use of many different VR applications.

Author Contributions: M.L., T.P.K., and F.T. conceived the main research idea about VR; M.L. and B.D. generated the bathymetric data; M.L. processed all data and developed the VR application under the supervision of F.T. and T.P.K.; M.L. wrote the manuscript with the support of T.P.K.; M.L. generated the illustrations, while B.D. and F.T. proofread the manuscript.

Funding: This research was supported by Alfred Wegener Institute, Helmholtz Centre for Polar and Marine Research, and HafenCity University Hamburg, Lab for Photogrammetry \& Laser Scanning.

Acknowledgments: The authors express their gratitude to all interviewees whose passionate participation and input contributed to the successful validation of the VR application. Furthermore, the use of the DEMs of the Arctic DEM Project and the DEMs provided by the Polar Geospatial Centre under NSF-OPP awards 1043681, 1559691 , and 1542736 is gratefully acknowledged.

Conflicts of Interest: The authors declare no conflict of interest.

\section{References}

1. Imhof, E. Kartographische Geländedarstellung; Walter de Gruyter: Berlin, Germany, 1965.

2. Zanini, M. Dreidimensionale synthetische Landschaften: Wissensbasierte Dreidimensionale Rekonstruktion und Visualisierung Raumbezogener Informationen. Available online: http://www.igp-data.ethz.ch/ berichte/Blaue_Berichte_PDF/66.pdf (accessed on 9 January 2019).

3. Virtual Reality. Available online: https://www.dictionary.com/browse/virtual-reality (accessed on 5 December 2018).

4. Dörner, R.; Broll, W.; Grimm, P.; Jung, B. Virtual und Augmented Reality (VR/AR): Grundlagen und Methoden der Virtuellen und Augmentierten Realität; Springer: Berlin, Germany, 2014.

5. Freina, L.; Ott, M. A Literature Review on Immersive Virtual Reality in Education: State of The Art and Perspectives. eLearning \& Software for Education. Available online: https:/ / www.researchgate.net/publication/280566372_A_Literature_Review_on_Immersive_Virtual_ Reality_in_Education_State_Of_The_Art_and_Perspectives (accessed on 9 January 2019).

6. Portman, M.E.; Natapov, A.; Fisher-Gewirtzman, D. To go where no man has gone before: Virtual reality in architecture, landscape architecture and environmental planning. Comput. Environ. Urban Syst. 2015, 54, 376-384. [CrossRef]

7. Jerald, J. The VR Book: Human-Centered Design for Virtual Reality; Association for Computing Machinery and Morgan \& Claypool: New York, NY, USA, 2016.

8. McCaffrey, M. Unreal Engine VR Cookbook; Addison-Wesley Professional: Boston, MA, USA, 2017.

9. Fuchs, P. Virtual Reality Headsets - A Theoretical and Pragmatic Approach; CRC Press: London, UK, 2017.

10. Gutiérrez, M.A.; Vexo, F.; Thalmann, D. Stepping into Virtual Reality; Springer: London, UK, 2008.

11. Kersten, T.; Tschirschwitz, F.; Deggim, S. Development of a Virtual Museum including a 4D Presentation of Building History in Virtual Reality. Inter. Arch. Photogramm. Remote Sens. Spat. Inf. Sc 2017, 42, 361-367. [CrossRef]

12. Tschirschwitz, F.; Richerzhagen, C.; Przybilla, H.-J.; Kersten, T. Duisburg 1566-Transferring a Historic 3D City Model from Google Earth into a Virtual Reality Application. PFG J. Photogramm. Remote Sens. Geoinf. Sci. 2019, 87, 1-10. [CrossRef] 
13. Deggim, S.; Kersten, T.; Tschirschwitz, F.; Hinrichsen, N. Segeberg 1600-Reconstructing a Historic Town for Virtual Reality Visualisation as an Immersive Experience. Inter. Arch. Photogramm. Remote Sens. Spat. Inf. Sci. 2017, 42, 87-94. [CrossRef]

14. Kersten, T.; Büyüksalih, G.; Tschirschwitz, F.; Kan, T.; Deggim, S.; Kaya, Y.; Baskaraca, A.P. The Selimiye Mosque of Edirne, Turkey-An Immersive and Interactive Virtual Reality Experience using HTC Vive. Inter. Arch. Photogramm. Remote Sens. Spat. Inf. Sci. 2017. [CrossRef]

15. Kersten, T.; Tschirschwitz, F.; Lindstaedt, M.; Deggim, S. The historic wooden model of Solomon's Temple: 3D recording, modelling and immersive virtual reality visualisation. J. Cult. Herit. Manag. Sustain. Dev. 2018, 8, 448-464. [CrossRef]

16. Mat, R.C.; Shariff, A.R.M.; Zulkifli, A.N.; Rahim, M.S.M.; Mahayudin, M.H. Using Game Engine for 3D Terrain Visualisation of GIS Data: A Review. Available online: https://pdfs.semanticscholar.org/3c03/ 9566fdf573dad91058c9bfab98f98a1c7e22.pdf (accessed on 9 January 2019).

17. Herwig, A.; Paar, P. Game Engines: Tools for Landscape Visualization and Planning? Available online: https://www.researchgate.net/profile/Philip_Paar/publication/268212905_Game_Engines_Tools_ for_Landscape_Visualization_and_Planning/links/5464ab2b0cf2cb7e9dab8bc5.pdf (accessed on 9 January 2019).

18. Thöny, M.; Billeter, M.; Pajarola, R. Vision paper: The future of scientific terrain visualization. In Proceedings of the 23rd SIGSPATIAL International Conference on Advances in Geographic Information Systems, Seattle, WA, USA, 3-6 November 2015.

19. Mat, R.C.; Mahayudin, M.H. Using Game Engine for Online 3D Terrain Visualization with Oil Palm Tree Data. J. Telecommun. Electron. Comput. Eng. 2018, 10, 93-97.

20. Wang, J.; Wu, F.; Wang, J. The Study of Virtual Reality Scene Making in Digital Station Management Application System Based on Unity3D. In Proceedings of the 2015 International Conference on Electrical, Computer Engineering and Electronics, Jinan, China, 29-31 May 2015.

21. Tsai, F.; Chiu, H.C. Adaptive Level of Detail for Large Terrain Visualization. Available online: http://www. isprs.org/proceedings / xxxvii/congress /4_pdf/103.pdf (accessed on 9 January 2019).

22. Jakobsson, M.; Mayer, L.; Coakley, B.; Dowdeswell, J.A.; Forbes, S.; Fridman, B.; Hodnesdal, H.; Noormets, R.; Pedersen, R.; Rebesco, M.; et al. International Bathymetric Chart of the Arctic Ocean (IBCAO) Version 3.0. Encyclo. Mar. Geosci. 2014. [CrossRef]

23. ArcticDEM. Harvard Dataverse 2018. Available online: https://dataverse.harvard.edu/dataverse.xhtml? alias=pgc (accessed on 9 January 2019).

24. Government of Canada. Canadian Digital Elevation Model. Natural Resources Canada 2018. Available online: https: / / open.canada.ca/data/en/dataset/7f245e4d-76c2-4caa-951a-45d1d2051333 (accessed on 19 December 2018).

25. Lütjens, M. Immersive Virtual Reality Visualisation of the Arctic Clyde Inlet on Baffin Island (Canada) by Combining Bathymetric and Terrestrial Terrain Data. Master Thesis, HafenCity University, Hamburg, Germany, 2018.

26. O'Flanagan, J. Game Engine Analysis and Comparison. Available online: https://www.gamesparks.com/ blog/game-engine-analysis-and-comparison / (accessed on 27 January 2019).

27. Lawson, E. Game Engine Analysis. Available online: https://www.gamesparks.com/blog/game-engineanalysis/ (accessed on 27 January 2019).

28. Painter, L. Hands on with HTC Vive Virtual Reality Headset. 2015. Available online: http:/ /www.pcadvisor. co.uk/feature/gadget/hands-on-with-htc-vive-virtual-reality-headset-experience-2015-3631768/ (accessed on 28 January 2019).

29. HTC Corporation. Vive PRE User Guide. Available online: http://www.htc.com/managed-assets/shared/ desktop/vive/Vive_PRE_User_Guide.pdf (accessed on 6 December 2018).

30. Epic Games, Inc. World Composition User Guide. Available online: https://docs.unrealengine.com/en-us / Engine/LevelStreaming/WorldBrowser (accessed on 3 December 2018).

31. Den, L. World Machine to UE4 using World Composition. Epic Games, Inc., 2015. Available online: https: //wiki.unrealengine.com/World_Machine_to_UE4_using_World_Composition (accessed on 4 December 2018).

32. RGI Consortium. Randolph Glacier Inventory-A Dataset of Global Glacier Outlines: Version 6.0. Available online: https:/ / www.glims.org/RGI/00_rgi60_TechnicalNote.pdf (accessed on 9 January 2019). 
33. HTC Corporation. SPECS \& DETAILS. Available online: https://www.vive.com/uk/product/\#vive-spec (accessed on 15 December 2018).

34. Lurton, X.; Lamarche, G.; Brown, C.; Lucieer, V.; Rice, G.; Schimel, A.; Weber, T. Backscatter Measurements by Seafloor-Mapping Sonars. Guidelines and Recommendations. 2015. Available online: http:/ /geohab. org/wpcontent/uploads/2013/02/BWSG-REPORT-MAY2015.pdf (accessed on 5 December 2018).

(c)

(c) 2019 by the authors. Licensee MDPI, Basel, Switzerland. This article is an open access article distributed under the terms and conditions of the Creative Commons Attribution (CC BY) license (http:/ / creativecommons.org/licenses/by/4.0/). 